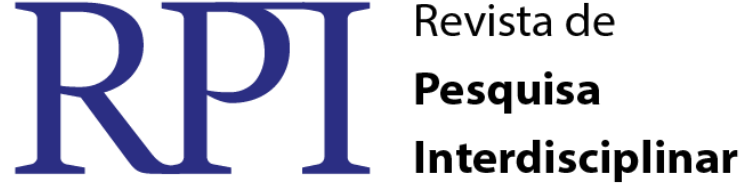

\section{CARTOGRAFIA IMAGÉTICA DA EDUCAÇÃO INFANTIL EM CAJAZEIRAS: PERSPECTIVAS CULTURAIS}

\author{
Sara Sheyla Santana Alves ${ }^{1}$ \\ Sara Samita Santana Alves ${ }^{2}$
}

\begin{abstract}
RESUMO
O artigo apresenta as primeiras discussões acerca da cultura da educação infantil em Cajazeiras gerada em sala de aula, na disciplina Fundamentos e Metodologia da Educação Infantil I do Curso de Pedagogia da UFCG/CFP/UAE, onde os estudantes propuseram pensar os espaços para concretização do educar e cuidar na escola púbica e, dai analisar as práticas e os modelos teóricos e metodológicos adotados nesses espaços. O projeto emergiu da inquietação dos alunos frente as suas observações de escolas em que os espaços físicos com sua estrutura (material pedagógico, parquinhos, salas de aula, entre outras) indicam a tendência pedagógica adotada nas escolas e dificulta a realização das atividades das professoras. A questão de partida é sobre como vem se configurando a cultura de adequação dos espaços, considerando seus espaços geográficos e físicos, na aplicação de conhecimentos acadêmico-científicos na escola voltado para as crianças de 0 a 5 anos de idade? Desse modo, pode-se pensar quais caminhos a UFCG poderia traçar, junto com as professoras formadoras e em atuação na Educação Infantil, para consolidar as proposições atuais de educação pela articulação entre arte e ciência na formação de professores? O pressuposto eleito para o projeto extensionista é de que educar e cuidar na Educação Infantil estão diluídos e carecem de entendimento por parte dos professores atuantes ávidos por sua clarificação. Neste sentido, o objetivo é elaborar uma cartografia imagética para compreender a cultura da Educação Infantil em Cajazeiras por parte dos professores, a partir da análise da compreensão desses acerca dos direitos de aprendizagem, como atitudes práticapoiéticas.
\end{abstract}

Palavras-chave: Educação Infantil. Imagens. Cuidar e Educar.

\section{IMAGECTICAL CARTOGRAPHY OF CHILDREN EDUCATION IN CAJAZEIRAS: CULTURAL PERSPECTIVES} ABSTRACT

This article presents the first discussions about the culture of children 's education in Cajazeiras generated in the classroom, in the discipline Fundamentals and Methodology of Early Childhood Education I of the Pedagogy Course of UFCG / CFP / UAE, where the students proposed to think about spaces for Educate and care in the public school, and then analyze the practices and the theoretical and methodological models adopted in these spaces. The project emerged from the students' concern about their observations of schools in which the physical spaces with their structure (pedagogical material, playgrounds, classrooms, among others) indicate the pedagogical tendency adopted in schools and make it difficult for the teachers to carry out their activities. The starting point is how is the culture of space suitability, considering its geographic and physical spaces, in the application of academic-scientific knowledge in the school aimed at children from 0 to 5 years of age? In this way, it is possible to think about which paths the UFCG could draw, together with the teachers educators and in action in the Infantile Education, to consolidate the present propositions of education by the articulation between art and science in the formation of teachers? The assumption chosen for

\footnotetext{
${ }^{1}$ Acadêmica no $6^{\circ}$ período do curso de Pedagogia, da Universidade Federal de Campina Grande - UFCG. EMAIL: sarasheyl@gmail.com

2 Acadêmica no $6^{\circ}$ período do curso de Pedagogia, da Universidade Federal de Campina Grande - UFCG. EMAIL: sarasamitas@gmail.com
} 
the extension project is that educating and caring in Early Childhood Education is diluted and lacking understanding on the part of working teachers eager for clarification. In this sense, the objective is to elaborate an imaginary cartography to understand the culture of Early Childhood Education in Cajazeiras by teachers, based on the analysis of their understanding of learning rights, as practicalpoietic attitudes.

Keywords: Early Childhood Education. Images. Caring and Educating.

\section{INTRODUÇÃO}

O texto apresenta o projeto "Cartografia imagética da Educação Infantil em Cajazeiras: perspectivas culturais" foi desenvolvido na disciplina: Fundamentos e Metodologias da Educação Infantil I, com a professora Cristina Novikoff. O objetivo desse texto é apresentar o percursso do projeto, como parte da atividade do projeto que teve como objetivo elaborar uma cartografia imagética para se compreender a cultura da Educação Infantil em Cajazeiras por parte dos professores, a partir da análise da compreensão desses acerca dos direitos de aprendizagem, como atitudes prática-poiéticas. Na sequência, promover oficinas de formação continuada para professores da Educação Infantil, aprofundando temas da discussão do atual documento de consulta pública do governo federal intitulado "Base Nacional Comum Curricular"- BNCC (2016) em relação aos direitos de aprendizagem e aos campos de experiências e objetivos de aprendizagem da criança na Educação Infantil.

O projeto apresenta relevância ao se observar a atual conjuntura do Brasil de desmantelamento de conquistas sociais e educacionais. Uma delas recai sobre o BNCC que foi abortado. Assim, o conjunto de sua relevância se encerra nas dimensões social, acadêmica e científica, abaixo relacionadas de modo imbricado.

A relevância acadêmica está marcada por distintos aspectos pedagógicos interligados em redes de interdependência. $\mathrm{O}$ primeiro diz sobre o desenvolvimento do presente projeto que enceta contribuição do aprofundamento da discussão sobre a cultura da Educação Infantil frente o educar e cuidar para os professores em formação e em atuação. Nesse aspecto, vale destacar que os professores em formação inicial serão contemplados com o projeto, pois responde parte das questões levantadas em aula na disciplina Fundamentos e Metodologia da Educação Infantil I sobre o tema direitos da criança e cultura da infantilização. É imprescindível ressaltar que o projeto guarda relevância acadêmica a partir da valorização das atitudes pedagógicas e acadêmicas, originárias de sala de aula.

Outro aspecto da dimensão acadêmico e científico é que o projeto é uma proposta coletiva entre professor em formação e em atuação na escola de educação infantil e o RPI Revista de Pesquisa Interdisciplinar, Cajazeiras, v. 1, Ed. Especial, 237 - 248, set/dez. de 2016. 
professor formador, como forma de enfrentamento das dificuldades dos professores da Educação Infantil em trabalhar seus conhecimentos acadêmicos e científicos. Aqui trazemos outro importante ponto de interdependência que é o problema levantado em sala de aula e que vai ser tratado com a interdisciplinaridade entre arte e educação, com uso de imagens. Tal abordagem de tratamento de um tema abre a possibilidade de se configurar um instrumento de autoconhecimento na formação de professores - as imagens fotográficas. Tais atitudes frutos da metodologia ativa adotada na referida disciplina denota valor metodológico, na dimensão acadêmica, mas também social por se projetar para atender as necessidades do professor em atuação em sua formação continuada e, assim, a sociedade ganha professores críticos e criativos.

Outra relevância acadêmica está no posicionamento político da educação adotada, ou seja, o projeto a ser desenvolvido é marcado pela funcionalidade e aplicação da interdisciplinaridade e o desenvolvimento teórico com as ancoragens epistemológicas acerca de cultura, educar, cuidar, autoimagem e autoformação corroboram com as novas políticas de Educação Infantil, de modo ético e estético.

Os resultados obtidos no estudo planejado, dentro do presente projeto, servirão para consolidar e expandir experiências e conhecimentos científicos no Curso de Pedagogia da UFCG, no campus de Cajazeiras, marcando sua relevância científica.

Outro aspecto da relevância acadêmico-científica se delineia na formação científica integrada e articulada de professor-pesquisadores da graduação com professores atuantes na Educação Infantil, que compartilharão da convivência com jovens em formação no ensino superior, provocando a formação inicial e continuada de modo dialético.

Como relevância social, destacamos outro ponto importante, ou seja, o desenvolvimento deste projeto proporcionará um maior intercâmbio de conhecimento e estreitamento dos laços entre professores-pesquisadores e professores em atuação na escola voltada para a Educação Infantil e, consequentemente, um crescimento em projetos cooperativos e um fortalecimento da integração entre as instituições envolvidas.

\section{Dimensão Teórica}

Segundo Oliveira (2010) os termos infância precisa ser revisto com o novo conceito em uma ótica que englobe todos os requisitos possíveis que a criança seja vista não apenas como um simples bebezinho. Na verdade, a infância não é um campo de lacunas, silêncios e 
passividade nem está correta a imagem da criança na pedagogia como a de alguém muito frágil. A criança aparece nos dias atuais com uma nova identidade são elas curiosas e ativas com direitos e necessidades que precisam de um espaço adequado que lhe permita interagir, brincar e socializar-se.

No que se diz a respeito às creches, historicamente sempre foi vista como refúgio assistencial para a população, desde o período das grandes revoluções onde as mulheres ganharam espaço no mercado de trabalho. Dessa forma, houve a necessidade de se ter um ambiente para as crianças a uma esfera muito imediata. Assim, segundo Oliveira, as creches e pré-escolas precisam aproximar cultura, linguagem, cognição e afetividade como elementos constituintes do desenvolvimento humano e voltados para a construção da imaginação e da lógica, considerando a sociabilidade, a afetividade e a criatividade têm muitas raízes e gêneses. Acredito que o período da infância é o mais importante para a construção do ser humano sendo necessário se olhando com toda as suas especialidades, comparo este período igual a construção de uma casa se ela é firmada na rocha não terá problema com o tempo mais se o seu firmamento for na areia com material de má qualidade com o passar dos anos sua estrutura desabará.

Hoje, na educação infantil, o debate centra-se na autonomia de cada creche e préescola para elaborar e desenvolver seu projeto pedagógico e na necessidade de que esse projeto se comprometa com padrões de qualidade. Não se trata de aceitar qualquer modelo, mas de garantir qualidade no modelo educacional proposto. Pensamos que esta tarefa não é tão fácil, falar sobre a qualidade em educação e algo extremamente atual. É preciso investir em recursos, espaços adequados, na formação da qualidade dos professores para enfrentar as dificuldades do dia-a-dia que são encontrados no ambiente escolar e o comprometimento da comunicação da escola com praticas continuada, um currículo reflexivo elaborado de acordo com a realidade dos alunos. A ação educativa da creche e pré-escola deve interpretar de conhecer e aprender a enriquecer-se com a troca de experiências com outros indivíduos. O ser social é preparado para conviver com as diferenças do outro conscientizar-se de seus direitos e deveres, seres humanos autônomos, que saibam ouvir o outro respeitando suas necessidades de cada um e a situação educativa torna-se com isso o ambiente ideal para o cultivo de tolerância, do combate a preconceitos, do aprendizado com base nas diferenças.

No momento de consolidação da educação infantil como um direito da criança, conhecer a historia das instituições e das políticas públicas na área traçada dentro das demais lutas sociais apontam caminhos para entendermos suas contradições. Por muitos séculos a 
educação da criança era vista como obrigação das mães ou por outras mulheres, consequentemente a criança era vista como um adulto em miniatura após o desmame e seu período de dependência de outros era instruído para ajudar os adultos nas atividades do cotidiano, mesmo nas classes privilegiadas onde as crianças eram vista como algo divino, misterioso cuja transformação em adulto volta-se para o ambiente doméstico.

Nos séculos XV e XVI, houve a necessidade de novos modelos educacionais para responder aos desafios estabelecidos pela maneira como a sociedade européia se desenvolva, com isso surgiram os pioneiros da educação infantil pessoas com novas concepções acerca da educação da criança na primeira infância surgiram uma nova visão sobre como seria a educação da criança. Autores como Erasmo (1465-1530) e Montaigne (1483-1553) sustentaram que a educação deveria respeitar a natureza infantil, estimular a atividade da criança e associar o jogo à aprendizagem. Essa transformação na educação infantil passou por momentos difíceis com as transformações nos países Europeus de uma sociedade agrária mercantil para urbano manufatureira. Passagem dada por conflitos com a consequente produção de condições sociais. Podemos aduzir que não foi um momento muito fácil para as criações naquela época, pois as mesmas eram classificadas de acordo com sua condição social não tinha uma proposta instrucional formal, tais atividades eram voltadas para bons hábitos de comportamento e as escolas geravam uma proposta instrucional formal, tais atividades com foco em bons hábitos de comportamento. Assim, as escolas geravam uma rotina de atividades observadas e autodisciplina infelizmente como até hoje nos dias atuais. O básico sempre foi para os filhos dos operários e a educação foi mais votada para o ensino da obediência, moral e valorização do trabalho. O que se pode analisar de bom nessa época foi a diminuição dos índices de mortalidade entre as crianças que os pioneiros da educação favoreceram.

No inicio da idade moderna iniciou-se uma nova etapa de construção da ideia de educação infantil na Europa a revolução industrial foi um fato importante para essa transformação. A discussão sobre a escolaridade obrigatória se intensificou em vários países europeus nos séculos XVIII e XIX. Nesse momento a criança passou a ser vista como sujeito de necessidade e objeto de expectativas e cuidados, situado em um período de preparação para o ingresso no mundo dos adultos. O mesmo não acontecia ás crianças dos extratos sociais mais pobres. Entretanto o sistema de educação não era para todos. Destinava-se para os que podiam pagar, excluindo os menos favorecidos que eram encaminhados para reformadores protestantes que lutavam para uma educação para ricos ou pobres, uma vez que eles consideravam a educação um direito universal. Com isso os pioneiros da educação pré-escolar 
buscam descobrir formas de ensinar sem abusar sem punições físicas. Autores como Comênius, Rousseau, Pestalozzi, Decroly, Froebel e Montessori criam métodos pedagógicos com base para um ensino tento a criança como o centro. Novas propostas educacionais sobre a visão de desses pensadores, entre outros, influenciam ate os dias atuais a questão da educação de crianças. As suas teorias com ênfase nas instituições de educação infantil envolveu um longo processo. Seus modelos pedagógicos, voltados para atender populações socialmente desfavoráveis beneficiam até hoje escolas e instituições que adotam um modelo de ensino voltado para a criança como o centro de aprendizagem e o professor proporcionar atividades ou métodos pedagógicos que influenciou no processo de aprendizagem.

Acreditamos que educação é um processo desafiador em termos conceituais e práticos, pois marcam a cultura educacional. E, nesse sentido que se busca pensar a cultura da educação infantil. Como nos mostra Santos (2010, p.4) a cultura "é uma preocupação contemporânea, bem viva nos tempos atuais. É uma preocupação em entender os muitos caminhos que conduziram os grupos humanos às suas relações presentes e suas perspectivas de futuro". Daí abduz-se que os fatos que marcam as formas de se compreender algum processo de produção de conhecimento, como a educação nos permite sinalizar os conflitos entre modos diferentes de organizar a vida escolar e de se apropriar dos recursos cognitivos, culturais e tecnológicos da formação docente. E, é neste cenário que se concebe e objetiva a realidade.

Para Roberta Borges (2015, s/p) da divisão de Educação Infantil e Complementar (DEdiC) da Unicamp, apesar dos avanços em relação a legislação, diretrizes e propostas pedagógicas, que tem o objetivo de garantir um ambiente adequado e seguro, ainda há necessidade de preparo dos educadores. É preciso saber trabalhar com a família e com a comunidade. Alerta que esses são os espaços em que a criança passa a maior parte do tempo.

Outro aspecto em relação ao espaço diz do ambiente escolar em que as instituições têm pouco material estimulante, poucos equipamentos adequados e hoje está sujeita a se tornar muito acadêmica. Esse problema centra-se na ruptura entre teoria e prática, abrindo uma lacuna na formação de professores que saem dos cursos sem uma visão prática das atividades que devem realizar em sala de aula.

Para discuti o tema adotaremos a interdisciplinaridade não centrada no sujeito e na separação sujeito-objeto como ocorre nos trabalhos de Japiassú (1976) e Fazenda (1991, 2005), mas na interdisciplinaridade como processo histórico proposto por Jantsch e Bianchetti (2008) para pensar os problemas da cultura da infância em Cajazeiras no tempo histórico.

RPI Revista de Pesquisa Interdisciplinar, Cajazeiras, v. 1, Ed. Especial, 237 - 248, set/dez. de 2016. 
A interdisciplinaridade a ser adotada será a fomentada na perspectiva escolar, em que

[...] não tem a pretensão de criar novas disciplinas ou saberes, mas de utilizar os conhecimentos de várias disciplinas para resolver um problema concreto ou compreender um determinado fenômeno sob diferentes pontos de vista. Em suma, a interdisciplinaridade tem uma função instrumental. Trata-se de recorrer a um saber diretamente útil e utilizável para responder às questões e aos problemas sociais contemporâneos. (BRASIL, 2002, p. 21)

Os problemas contemporâneos frente à educação Infantil é notório com a falta de espaços, materiais e formação de professores, conforme descreve o relatório da infância da OCDE (BRASIL, 2009, p.185).

\begin{abstract}
As entrevistas atestam a precariedade dos cursos de magistério, com estágios meramente formais que não preparam professores para a realidade a ser enfrentada. Limitações também verificadas na formação em serviço, pois muitas vezes não existem horários previstos para o planejamento e reflexão em equipe e os modelos adotados não favorecem a integração de teoria e prática.
\end{abstract}

No mesmo documento é assinalado que "um bom programa de educação pré-primária prepara a criança para a escolarização formal como parte de um desenvolvimento holístico. A ênfase deve ser colocada num desenvolvimento equilibrado, não apenas no aspecto cognitivo, mas também nos aspectos social, emocional, comunicativo e físico" (BRASIL, 2009, 53).

Começamos por pensar no fato de que a cultura da educação infantil no Brasil, ainda está por ser feita e, como objeto caro a UFCG, em especial ao PROGERES, grupo de pesquisa interessado em contribuir para seu fortalecimento e materialização diante das novas diretrizes em elaboração no documento "Base Nacional Comum Curricular" (2016) nos propomos a sensibilizar os professores deste nível de ensino e tomar a arte pela fotografia para que as próprias professoras exercitem com suas crianças o uso da fotografia nos espaços escolares.

A fotografia como instrumento intelectual na aprendizagem, a partir da articulação entre a imaginação material e dinâmica de autoavaliação e avaliação na sala de aula.

A proposta da formação continuada é estabelecer um processo dialético em prol da sensibilização estética para superar o engessamento didático de apelo ao conteudismo ou normativo será o foco da formação continuada com as professoras.

RPI Revista de Pesquisa Interdisciplinar, Cajazeiras, v. 1, Ed. Especial, 237 - 248, set/dez. de 2016. 
A importância das Teorias da Educação para a formação do docente é uma constatação e uma justificação para a Pedagogia. É nos lugares de instituição da Pedagogia enquanto campo de conhecimento que elas se fazem presentes e as propagam.

A priori, evidencia-se que as teorias da educação inquirem o desenvolvimento da prática docente, na busca incessante de solucionar os problemas na relação entre o professor e o aluno, que podem ser influenciados por fatores culturais, socioeconômicos, religiosos, entre outros. Daí abstrair que a interação entre teoria e prática é essencial para uma formação pedagógica emancipatória e autônoma, motivo suficiente para afirmamos que o educador não deve se prender apenas a teoria, mas buscar métodos para colocá-la em prática, visando às diferenças sociais e as influências culturais que são encontradas no âmbito educacional.

Ao entender o pressuposto de que o educador deveria, somente, ensinar quando primeiro adquirir o conhecimento necessário, implica em afirmar o quanto é fundamental a busca, além das teorias conquistadas na sua formação, a práxis para desenvolver novas maneiras de ensinar, de forma clara e objetiva, o conhecimento para seus educandos, sem subestimar o conhecimento por eles já adquiridos no seu meio familiar e social.

Para a educação se materializar no sentido de articular a educação e a arte ciência, se fez necessário se empenhar esforços coletivos, com todos os alunos da disciplina "Teorias da educação" para se atentar para o valor da extensão.

Nesse sentido, que destacamos que a importância da extensão se acentua na contemporaneidade, momento de constantes mudanças impostas pela economia que atingem as diversas áreas sociais, inclusive a educação. Surgem, então, à necessidade de atualização dos conhecimentos da ciência da educação, de suas teorias e métodos de ensino para pensarmos sua materialização na escola e seu impacto.

A extensão aparece como dialogo aberto com a comunidade e, no presente projeto, implica em rever e reformular técnicas adotadas para preparar professores em atuação na educação básica para aplicação de novas práticas de ensino.

Vale destacar que durante a vida acadêmica do pedagogo são muitas as dificuldades apresentadas, segundo Donald Schon (2000) "a prática profissional do docente se caracteriza por apresentar situações de instabilidade e de incertezas nem sempre são resolvidos pelo profissional, pois seu repertorio de setores não da as respostas exigidas seu dia a dia do exercício da profissão".

Sendo assim, a reformulação dos pensamentos desse profissional (para prepará-lo pra essas instabilidades) é urgente e necessária, isso então só poderá ocorrer se a instituição 
responsável (Universidade) assumir seu papel de moldadora de profissionais e articula projetos de extensão que permitam a atuação desse profissional em formação dentre a sociedade em geral, principalmente com o publico infantil que representa o futuro.

As universidades, como instituição social tem o dever de com o apoio de o governo abrir oportunidades para a atuação do educador na própria sociedade, pois só assim ela permitira uma verdadeira formação de bons profissionais, competentes e aptos a provocar a mudança e consequentemente melhorias no Brasil e no mundo, pois só a boa educação pode promover tal feito. O ensino superior não pode está limitada a simples aprendizagem intercurricular, a extensão vinculada ao saber acumulado nas instituições universitárias, trabalha a democratização da aprendizagem interferindo em seu meio. O fórum de pró-reitores define a extensão universitária como sendo:

A extensão universitária é o processo educativo, cultural e cientifica que articula o ensino e a pesquisa de forma indissociável e viabiliza a relação transformadora entre universidade e sociedade. A extensão é uma via de mão dupla, com o transito assegurado a comunidade acadêmica, que encontrara, na sociedade, a oportunidade de elaboração das práxis de um conhecimento acadêmico. Docentes e discentes trarão um aprendizado que, submetido a reflexão teórica será acrescido aquele conhecimento. Esse fluxo, que estabelece a troca de saberes sistematizados, acadêmico e popular, terá como consequências a produção do conhecimento resultante do confronto com a realidade brasileira e regional, a democratização do conhecimento acadêmico e a participação efetiva da comunidade na atuação da universidade. Além de instrumentalizadora desse processo dialético de teoria/pratica, a extensão é um trabalho interdisciplinar que favorece a visão integrada do social. (Fórum Nacional, 1987)

Esse conceito apresenta uma extensão universitária democrática, que é instrumentador do processo dialético teoria/pratica e que problematiza de forma interdisciplinar possibilitando uma visão ampla e integrada da realidade social. Podemos afirmar que essa conceituação é expressivamente freireniana, nela encontramos a relação dialética, a sistematicidade, o reconhecimento do outro e de sua cultura a apropriação pelo outro do conhecimento com liberdade para transformá-lo.A ideia de uma extensão a serviço de um processo transformador, emancipatório, democrático e ainda de uma extensão desenvolvida no diálogo e no respeito a cultura local nos permite perceber quanto o pensamento freireniano foi marcante e está presente no conceito da extensão das universidades públicas brasileiras.

RPI Revista de Pesquisa Interdisciplinar, Cajazeiras, v. 1, Ed. Especial, 237 - 248, set/dez. de 2016. 
Concluímos assim que as atividades de extensão universitária são indispensáveis para o acadêmico, por proporcionar a aproximação da universidade com a comunidade e estimular profissionais mais críticos, mais abertos ao diálogo.

Enfim, com o estudo das teorias educacionais, os professores se tornam capazes de abrir caminhos para que o alunado possa construir sua própria aprendizagem, buscando novos métodos que tornem mais eficazes a assimilação e a compreensão do conhecimento adquirido, fazendo com que o discente não siga por direções previamente construídas, libertando-o das alienações impostas no seu caminho, permitindo que o mesmo desenvolva uma aprendizagem significativa. Levando em consideração todos esses aspectos relatados, pode se chegar a conclusão que as teorias para o docência são tão importantes quanto as práticas, pois, toda a sua fundamentação de ensino baseia-se nesses princípios, somente com tais teorias, vistas ao longo de sua vida acadêmica, poderá aplicar todos esses conceitos na prática, de uma forma que consiga de fato conhecer o seu aluno e interagir com ele, enfrentando todos os problemas que encontra no âmbito escolar ou fora dele.

\section{Resultados}

Ao envolver os professores e estudantes interessados na educação Infantil e na educação de projetos extensionistas por meio de carta convite para conclave em abril de 2016 foi surpreendente pela adesão de todos os alunos da disciplina

Como etapa inicial foram feitas distribuição de agendas e carta de compromisso com as escolas, estudantes. Segue que os estudantes foram acompanhando as ações planejadas no conclave, mas agora de modo fracionado, em razão das atividades e compromissos com outras disciplinas. Nota importante foi perceber que mesmo com o volume de tarefas eles se dispuseram partir para a etapa de captação de imagens de professores e estudantes da educação infantil. Nessa fase outra surpresa foi verificar a participação de outros alunos de outra turma. Ocorreu uma fusão de alunos que enriqueceu o banco de fotografias do projeto.

$\mathrm{O}$ tratamento de imagens para proteger a identidade dos participantes das imagens foi realizado e a criação de exposição itinerante de imagens da cultura da educação infantil em Cajazeiras está pronta.

A criação de oficina de formação continuada para professores da Educação Infantil, com aprofundando temas da discussão do atual documento de consulta pública do governo federal intitulado "Base Nacional Comum Curricular" (2016) em relação aos direitos de 
aprendizagem e aos campos de experiências e objetivos de aprendizagem da criança na Educação Infantil foi alterado, em razão da ruptura do governo atual. No entanto a parte prática e teórica em relação as atividades apropriada para as crianças estão prontas. A questão é apresentar a mesma com a discussão do momento político vigente.

E por último a produção de artigo científico com relato de experiência de estudantes envolvidos no projeto de extensão em tela é o que o presente texto materializa em sua primeira versão.

\section{Considerações Finais}

O projeto em andamento alcançou êxito no que se refere ao cumprimento das etapas programadas até a presente data. Ainda se encontra na sua fase final, mas já apresenta corpo para continuar na produção e difusão de conhecimentos.

As atividades desenvolvidas e a discussão da situação real das escolas de Cajazeiras em que o ensino público municipal e estadual sofre do esvaziamento político, não passaram despercebidas pelos estudantes. Apesar de não ter sido realizada a discussão com as professoras da rede pública o documento na sua totalidade, nem com os estudantes, a professora da disciplina apontou alguns pontos da relevância do BNCC como caracterização social e histórica da criança se pautar no respeito as condições e natureza psicoafetiva e biológicas da criança, da real necessidade da ludicidade entre outros aspectos que nos acenam a necessidade de revisão do planejamento e da estrutura escolar em Cajazeiras.

As teorias apesar de terem sido apresentadas e discutidas, ainda carecem de aprofundamento para que os estudantes possam elaborar os textos de modo mais critico. Muitos dos participantes, ou seja, os estudantes em formação da UFCG que se encontram na fase de estágio conseguem perceber e externar em suas narrativas orais outros problemas de ordem estrutural que estão atravancando a educação que as crianças e a sociedade cajazeirense almejam e merecem.

Em síntese, o projeto teve e terá relevância para a formação dos estudantes de pedagogia e para as escolas de Cajazeiras que se perceber na UFCG uma parceira na reconstrução do entendimento do que seja educação infantil, a sociedade como um todo será beneficiada.

\section{REFERÊNCIAS}

RPI Revista de Pesquisa Interdisciplinar, Cajazeiras, v. 1, Ed. Especial, 237 - 248, set/dez. de 2016. 
BRASIL. Resolução CNE/CP 1/2002. Diretrizes Curriculares Nacionais para a formação de professores para a educação básica, em nível superior, curso de licenciatura, de graduação plena. Brasília, DF. Disponível em: http://portal.mec.gov.br/cne/arquivos/pdf/rcp01_02.pdf. Acesso em: 23 de Ago. 2011. Ministério da Educação. Secretaria de Educação Básica. Política de educação infantil no Brasil: Relatório de avaliação / Ministério da Educação, Secretaria de Educação Básica. - Brasília: MEC, SEB; Unesco, 2009.

FAZENDA, Ivani Catarina Arantes. Praticas interdisciplinares na escola. 7. ed. São Paulo: Cortez, 1991.

Interdisciplinaridade: história, teoria e pesquisa. - São Paulo: Papirus, 2005.

JAPIASSU, Hilton. Interdisciplinaridade e patologia do saber. Rio de Janeiro: Ed. IMAGO, 1976.

JANTSCH, Ari Paulo, BIANCHETTI, Lucídio (Org.). Interdisciplinaridade: para além da filosofia do sujeito. Petrópolis: Vozes, 2008.

NOVIKOFF, C. Dimensões Novikoff: um constructo para o ensino-aprendizado da pesquisa. In ROCHA, J.G. e NOVIKOFF, C. (orgs.). Desafios da práxis educacional à promoção humana na contemporaneidade. Rio de Janeiro: Espalhafato Comunicação, p. 211-242, 2010

Os Caminhos da Construção Pedagógica: Instituindo o Ser Professor In: Escola Competente. $1^{\text {a }}$ ed. Rio de Janeiro: Wak Editora, 2003, v.01, p. 207-230.

OLIVEIRA, Zilma de Morais Ramos de. Educação Infantil: fundamentos e métodos. $6^{\text {a }}$. Edição. São Paulo: Cortez, 2010.

SANTOS, José Luiz dos. O Que é Cultura. 6ª edição. São Paulo: Editora Brasiliense, 2010. 